\title{
Correction to: Global and Japanese regional variations in radiologist potential workload for computed tomography and magnetic resonance imaging examinations
}

\author{
Kanako K. Kumamaru' ${ }^{1}$ Akihiro Machitori ${ }^{2} \cdot$ Ritsuko Koba $^{3,4} \cdot$ Shinpei ljichi $^{4} \cdot$ Yasuo Nakajima $^{3} \cdot$ Shigeki Aoki $^{1}$
}

Published online: 30 March 2018

() Japan Radiological Society 2018

\section{Correction to: Japanese Journal of Radiology https://doi.org/10.1007/s11604-018-0724-5}

In Results of Abstract, the first sentence should read as: The radiologist potential workload in Japan was 2.78-4.17 times higher than those in other countries.

In the original publication, in Figure 2, parts $\mathrm{C}$ and $\mathrm{D}$ are mistakenly labeled as A and $\mathrm{B}$. The corrected figure is given in this Correction. The original article was corrected.

The original article can be found online at https://doi.org/10.1007/ s11604-018-0724-5.

Kanako K. Kumamaru

k-kumamaru@juntendo.ac.jp

Akihiro Machitori

dmachitori@hospk.ncgm.go.jp

Ritsuko Koba

Ritsuko.Koba@ge.com

Shinpei Ijichi

Shinpei.Ijichi@ge.com

Yasuo Nakajima

y3naka@marianna-u.ac.jp

Shigeki Aoki

saoki@juntendo.ac.jp
1 Department of Radiology, School of Medicine, Juntendo University, 2-1-1 Hongo, Bunkyo-ku, Tokyo 113-8421, Japan

2 Department of Radiology, National Center for Global Health and Medicine, Kohnodai Hospital, Chiba, Japan

3 Department of Radiology, St. Marianna University School of Medicine, 2-16-1 Sugao, Miyamae-ku, Kawasaki, Kanagawa 216-8511, Japan

4 GE Healthcare Japan Corporation, 4-7-127 Asahigaoka, Hino-shi, Tokyo 191-8503, Japan 
Fig. 2 Scatter plot of the number of radiologists versus the number of examinations performed. a Number of CT examinations performed in each prefecture of Japan. b Number of MRI examinations performed in each prefecture of Japan.

c Number of CT and MRI examinations performed in each prefecture of Japan. d Number of CT and MRI examinations performed in each prefecture of Japan and in each country. In each figure, the line represents a linear regression with zero intercept and the shaded area indicates the $95 \%$ confidence intervals
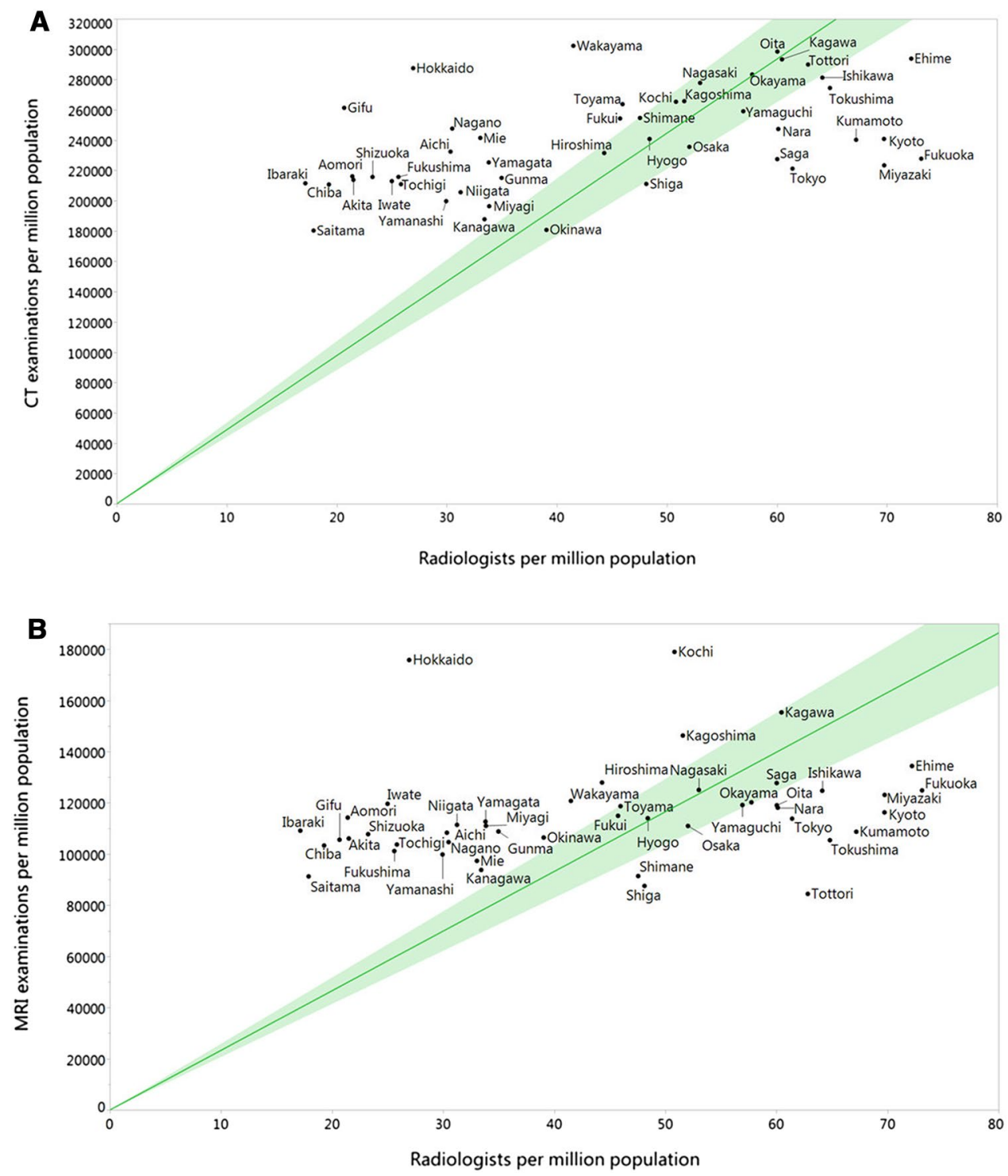
Fig. 2 (continued)

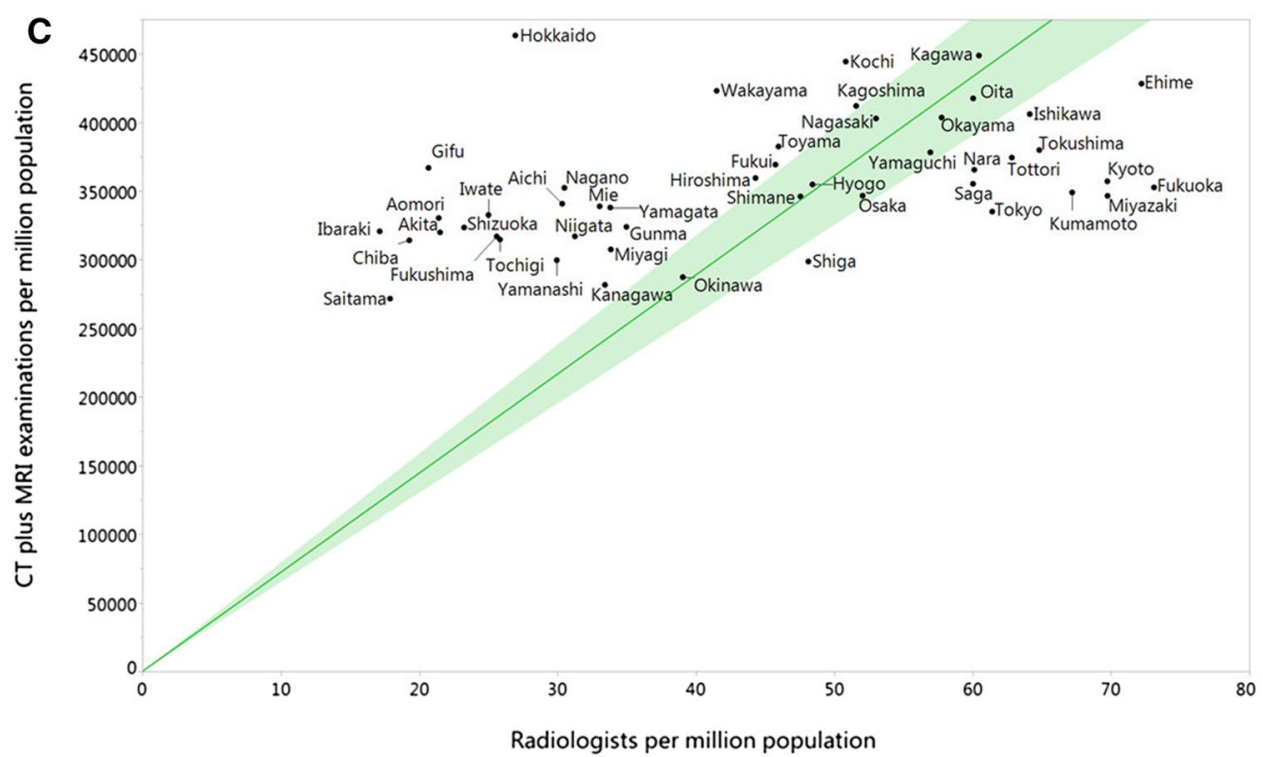

D

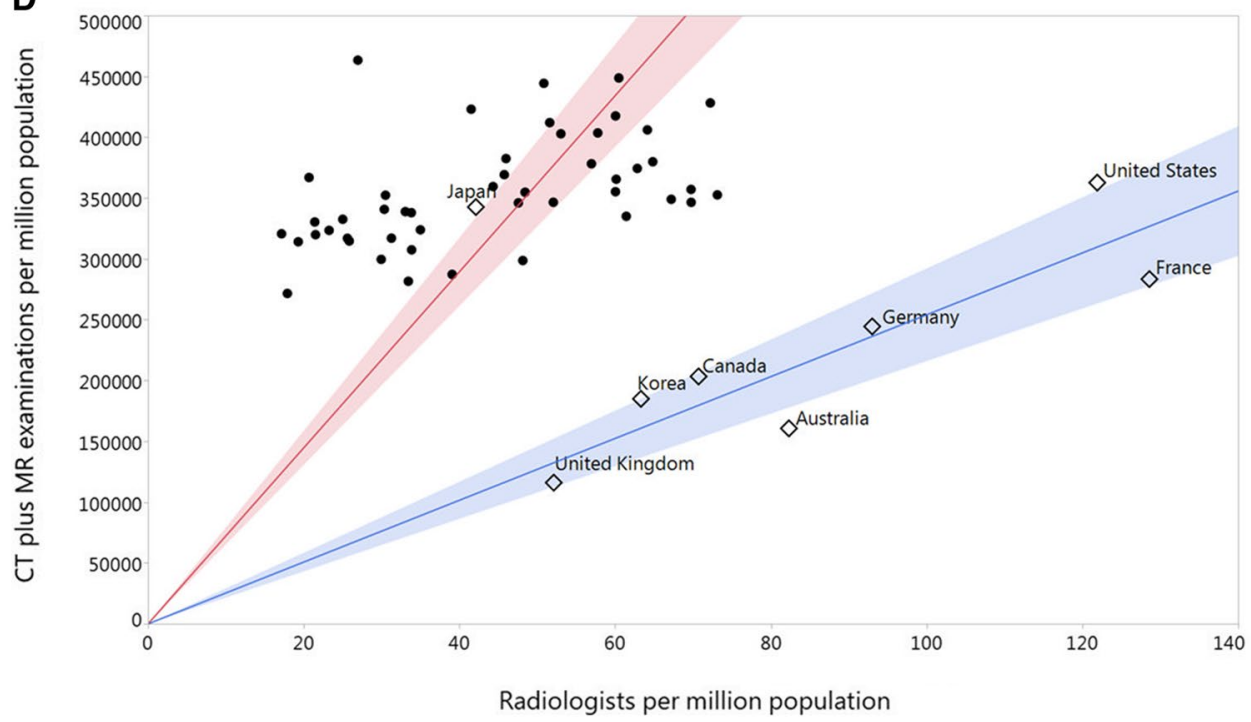

